\title{
LAS MARAS CENTROAMERICANAS: ¿VICTIMAS O VICTIMARIOS?
}

IRVING GARCÍA ESTRADA

Licenciado en Antropología Social - Universidad Autónoma del Estado de México (UAEM), Toluca, México

Maestrante en Humanidades: Estudios Latinoamericanos - UAEM, Toluca, México

Docente Investigador - Toluca, México

RESUMEN: Actualmente Latinoamérica enfrenta diversos fenómenos ligados a la(s) violencia(s); en el caso centroamericano, ha sido escenario del ejercicio de violencia, lo cual ha permeado las estructuras económicas, políticas y sociales. A mediados de 1970, bajo un sentido de identidad y pertenencia, y a través de los flujos migratorios, se empieza a gestar un fenómeno social conocido como las maras; hoy día, tal fenómeno va en aumento.

Las maras representan un problema que ha rebasado a los gobiernos involucrados, no parecen haber programas de combate al fenómeno desde una perspectiva más humana y con carácter de responsabilidad social. Se enfrenta un fenómeno violento, con una estructura primordialmente juvenil, que plantea una disyuntiva: por un lado está la aplicación de la Ley, que sin minimizar el problema lo ha llevado a situaciones extremas. En contraparte, discursos por los Derechos Humanos, muestran que el marero antes de ser delincuente es un ser humano -aspecto expuesto en estudios académicos-; si las maras asumen dicha identidad, se debe a la ausencia de alternativas de subsistencia.

Palabras claves: Centroamérica, Flujos Migratorios, Maras, Violencia, Identidad, Contingencia.

ABSTRACT: Latin America currently faces a number of phenomena linked to the violence. In the Centro America case, this place has been the scene of violence, which has permeated the economic, political and social structures. In mid-1970, under a sense of identity and belonging, through migratory flows, it begins to develop a social phenomenon known as maras, today, this phenomenon is increasing.

Maras are a problem which has overtaken the governments involved; apparently don't have programs to combat the phenomenon from a more human perspective and a social responsibility character. It faces a violent phenomenon, with a youth structure, which poses a dilemma: on one side is the application of the law, without minimizing the problem and that has led to extreme situations. In contrast, the speech on Human Rights shows that the marero before being criminal is a human (aspect exposed in academic studies) if the maras have that identity, is due to the absence of alternative livelihoods

Key words: Centro America, Central Migratory Flows, Gangs, Violence, Identity, Contingency. 
Vivimos en el comienzo de un siglo que se evidencia con grandes cambios a nivel mundial, pero que al mismo tiempo conlleva cambios en lo individual, se sacuden los cimientos fundamentales de la sociedad en su conjunto y de las culturas en particular, sobre todo las de mayor progreso en el sentido amplio de la palabra; hoy se cuestiona a la mayoría de estructuras, de instituciones, de paradigmas, de conductas y comportamientos y las respuestas no parecen ser muy halagadoras.

Día a día Latinoamérica nos presenta diferentes rostros que en su mayoría surgen de las crisis sociales, políticas, económicas, culturales, entre otras; lo cual nos conduce a reflexionar en un primer orden de ideas sobre el papel del Estado, que empieza a perder su capacidad para dar respuesta satisfactoria a las múltiples problemáticas, y que se desdibuja ante la gama de inconsistencias que debe soportar la sociedad en su conjunto.

Si bien Latinoamérica presenta un repunte en el mejoramiento respecto a la esperanza de vida de sus habitantes, y ha sido capaz de reducir la mortalidad y el analfabetismo, el problema que vienen soportando como un gran lastre es sin duda la desigualdad, porque a medida que el tiempo transcurre, la brecha entre los extremos va siendo cada vez mayor. Hoy día la región de Latinoamérica es la de mayor desigualdad en el mundo según la propia Organización de las Naciones Unidas (ONU). Cada vez son menos los que tienen más y son más los que tienen menos.

La desigualdad económica y social en Latinoamérica es persistente, tiene su origen fundamentalmente en las características de la organización económica, social y política, cuyos orígenes bien podemos trasladarlos a la época de la Conquista española. Y cuya herencia ha venido perdurando a lo largo de los siglos por la fuerza política de las élites y la resistencia de instituciones y normas sociales, económicas y políticas que, de hecho, en lugar de reducirla, la han ido reproduciendo.

En Latinoamérica, la desigualdad sobre todo económica es ofensiva porque la riqueza coexiste con la miseria. Además, la desigualdad está asociada a factores raciales y étnicos que tienen sus raíces históricas en el tratamiento que se ha dado a ciertos grupos a lo largo de los siglos. La desigualdad también resulta denigrante porque se perpetúa a través de mecanismos como la corrupción, el tráfico de influencias, la discriminación y la capacidad de controlar la agenda de políticas públicas para beneficio propio por parte de la población de mayores recursos económicos o de grupos corporativos poderosos.

Es bajo este contexto donde pretendemos mostrar una pequeña parte que si bien no es producto en su totalidad de las desigualdades, si es un elemento primordial en la conformación y permanencia del fenómeno centroamericano que vincula a la criminalidad con sus condicionados matices de pandillerismo, rencillas callejeras o de delincuencia común, particularmente en El Salvador, Guatemala y Honduras, y que se conoce como las maras.

\section{Las Maras: un breve recuento}

En principio me parece pertinente mencionar que al hablar de maras o pandillas se favorece el sustentar un estereotipo que se concentra en los jóvenes, no sólo porque los términos tienen ya un contenido negativo, sino porque así se segrega a la parte de la 
juventud que supuestamente no es sana y presenta una conducta violenta.

Esta visión de dos tonos blanco/ negro no hace justicia a la vida real de la totalidad de la juventud actual; sobre todo, no comprende los motivos, la percepción de sí mismos y la manera en que se organizan los jóvenes miembros de las maras. El intento de denominaciones neutrales llámese grupos espontáneos, grupos informales, agrupaciones juveniles, para escapar a los estereotipos, tampoco nos permite un mayor avance en la comprensión del fenómeno por ser muy generales y no tomar en cuenta las características propias del fenómeno.

Creo pertinente entender a los jóvenes no como meros recipientes vacíos que son rellenados por adultos a los cuales solamente imitan, sino como sujetos pensantes, con ideas propias, con proyectos de vida y capaces de crear sus propias expresiones y pautas culturales. En el caso de las pandillas, se trata de un fenómeno social múltiple, que abarca desde pequeños grupos de esquineros ${ }^{1}$ hasta estructuradas organizaciones que llegan a tener carácter internacional, con peculiaridades en cada grupo. Hay diferencias entre las pandillas de cada país y también las pandillas nacionales se van transformando con el paso del tiempo. Esto mismo aplica en el caso de las maras.

Tenemos presente que como grupo social, los jóvenes están vinculados a su entorno, al ambiente económico, social, político y cultural presente en cualquier etapa de la historia de un país o de una ciudad, y de esta relación dependerán los mecanismos, acuerdos, visiones y formas de convivencia que

1. Término coloquial con que se reconoce a los jóvenes que se reúnen con frecuencia en las esquinas para pasar el rato con los amigos. se hayan establecido entre ellos y su sociedad; de ella también dependerá la imagen pública de los jóvenes, su percepción popular y las formas que encuentran para asociarse entre sí.

Los jóvenes no son un grupo homogéneo, más bien el concepto de juventud:

Encierra en sí mismo la suma de numerosos grupos, muy distintos que algunas veces llegan a ser antagónicos... no todos los jóvenes son delincuentes, ni todos los delincuentes son jóvenes, pero existe cierta tendencia construida socialmente que con frecuencia, relaciona estos dos conceptos hasta llegar a hablar especificamente de una delincuencia juvenil ${ }^{2}$.

¿Pero qué son las maras? La idea de maras que mayor difusión ha tenido es quizá la que nos lleva a entenderlas como aquellas bandas delincuenciales surgidas del paradigma callejero centroamericano de los últimos años. "Pandillas organizadas en la comisión de delitos, dedicadas a la profesionalización de la violencia, el robo y el asesinato"3. Lo complejo de la situación es que no se ha logrado concretar una definición que evite en principio caer en relativismos y tratar de lograr una mayor objetividad para entender este fenómeno social.

En segunda instancia tenemos que la idea de mara se construye a partir de los discursos locales de El Salvador, Guatemala, Honduras y Nicaragua, en un primer plano nos remite a la idea de agrupación o asociación de

2. CASTILLO BERTHIER, Héctor. "Pandillas, jóvenes y violencia”. En: Desacatos número 14: Juventud, exclusión y violencia, Revista de Antropología Social, cuatrimestral. México: Ciesas, 2004, pp. 105-126.

3. LARA KLAHR, Marco. Hoy te toca la muerte. El imperio de las Maras visto desde dentro. México: Planeta, 2006. 
amigos, sin la condición de violencia. Es mediante una recurrente figura mediática, que las maras han devenido en violencia, asesinato, robo, violación, delincuencia, secuestro y pandillerismo. Estos elementos existen y definen la conducta de un número significativo de mareros, pero resulta abusivo etiquetar a todo marero de delincuente. En la estigmatización de las maras también participan figuras institucionales, en el marco de su estrategia de generar/utilizar el miedo como recurso de legitimación, quienes trastocan o limitan los derechos ciudadanos y humanos, a costa incluso de vidas inocentes.

Las maras deben entenderse como una variante de la cultura de sobrevivencia de los pobres y de los rechazados, como un reflejo de la violencia extendida y practicada por todas partes en Latinoamérica. Como la consecuencia de las diferentes problemáticas y situaciones que enfrenta Latinoamérica. En un estudio sobre las formas y causas de la violencia en $\mathrm{El}$ Salvador, el sociólogo salvadoreño José Miguel Cruz habla de una cultura de la violencia, a la que entiende como "la creación de valores y normas que legitiman y conceden un privilegio al uso de la violencia en cualquier ámbito frente a otras formas de comportamiento social"4.

Mientras que las pandillas callejeras son generalmente vistas como problemas de tipo criminal con grados variantes de sofisticación y alcance, algunas pandillas han evolucionado o se han transformado en entidades potencialmente más peligrosas. En muchas ciudades alrededor del mundo,

4. CRUZ, J.M. Los factores posibilitadores y las expresiones de la violencia en los noventa. Estudios Centroamericanos (ECA), 588, 1997, pp. 997-992. especialmente en las zonas pobres carentes de leyes y con gobiernos débiles, la inseguridad e inestabilidad dominan a los grupos armados organizados, en el caso de Centroamérica las maras son las que dominan.

De sus orígenes en 1970 a la fecha las maras se han ido transformando, e incluso hoy se habla de la tercera generación, que son las que nos ocupan en este caso. Las maras de tercera generación residen en la intersección entre la delincuencia, el crimen organizado y el narcotráfico. Son producto de los cambios en la organización de la sociedad, son el resultado de la confluencia de la globalización y de los avances tecnológicos que modifican a las economías. Lo que ha contribuido a documentar y tratar de explicar el fenómeno de las pandillas delictivas y maras en Centroamérica como fenómenos sociales, principalmente tiene que ver con el incremento de la violencia en general. Una de las primeras definiciones sobre pandillas, es la que aporta el sociólogo Frederik Thrasher, quien las entiende como:

Un grupo intermedio que surge de manera espontánea para luego consolidarse por medio de la vivencia de conflictos... El resultado de este comportamiento colectivo es una tradición, una estructura interna no reflexiva, de espíritu grupal, solidaridad, moral, conciencia grupal y la unión con un determinado territorio local ${ }^{5}$.

Un aporte fundamental de tal estudio lo es también el establecimiento de la premisa de que toda pandilla tiene un aspecto territorial, además de establecer que el proceso de formación es un continuo flujo y reflujo, pero

5. THRASHER, Frederik M. The gang. A study of 1313 gangs in Chicago. Chicago: University of Chicago Press, 1927, p. 46. 
nótese que la condición de violencia no aparece como algo asociado a la pandilla, y que hoy día es una de las principales características que se les atribuye tanto a las pandillas como a las maras.

Actualmente la violencia psicológica y los enfrentamientos armados tienen un papel central en las maras y pandillas. Pero aunque la mayoría de mareros cometen actos fuera de la ley, sería quedarse muy corto considerarlos como protagonistas de una subcultura criminal. Y es sólo a través del contacto directo del investigador con los mareros que se puede entender, que en su mayoría poseen razones para estar en las maras que van más allá del simple interés en involucrarse en situaciones delictivas.

$\mathrm{Y}$ es precisamente en esta última premisa donde los estudios académicos no han dado la importancia suficiente, además que bajo ese tenor se presenta la presunta violación a los Derechos Humanos. De lo cual asentimos que se debe tomar en conjunto y con la idea de tener una visión más objetiva respecto a las maras, las condiciones socio- culturales, históricas, políticas y económicas, y la Declaración Universal de los Derechos Humanos en la implementación de los sistemas jurídicos.

\section{Las maras como víctimas}

A nivel mundial se suscitan una serie de cambios de diversa índole como son la falta de una estabilidad económica, política o social y las causas que estas generan; el desempleo, la inseguridad, la pobreza, el bajo nivel educativo; por tanto, surgen una serie de fenómenos y situaciones que inmiscuyen en primer grado a países con menor índice de desarrollo como en el caso centroamericano, pero las repercusiones se hacen visibles incluso en los países desarrollados.

En el contexto latinoamericano, podemos observar que compartimos similitudes, al ver que somos partícipes entre otras cosas de situaciones históricas, de condiciones geopolíticas, de condiciones de pobreza y de desigualdad social, de falta de empleo, de la expulsión masiva de migrantes, de factores como el incremento en la producción, distribución y consumo de drogas, el fácil acceso a armas de fuego, la creciente inestabilidad política; pero también debemos recordar que a nivel local las diferencias se acentúan con tal grado de ser capaces de sostener identidades y condiciones particulares.

Subsecuentemente dichas circunstancias, se han conjugado para contribuir en gran parte con el surgimiento y proliferación de fenómenos sociales vinculados al uso de la violencia, en algunos casos auspiciados por los propios gobiernos; en otros como respuesta a la falta de satisfactores económicos primordialmente. Las maras son producto en gran medida de todos esos factores, y que en suma con la falta de oportunidades, es ya una forma de vida que les ha permitido subsistir no sólo a los mareros sino a las familias completas.

En toda esta dinámica multifactorial, el papel de Estados Unidos de América (EE.UU.) resulta trascendental; si bien es uno de los ocho países que literalmente mueven al mundo, con una las economías más sólidas e importantes, lo cual lo convierte en un gran receptor de migrantes, el punto a destacar es cómo está percibiendo y tratando de resolver el fenómeno de las maras, que son ya una amenaza a su seguridad nacional. 
En consecuencia han surgido unidades especiales para combatir a las pandillas donde se incluyen a las maras como el llamado Grupo antipandillas Crash Unit (The Community Resources Against Street Hoodlums) del Departamento de Policía de Los Ángeles) desmantelado hacia el año 2000, pero que ha dejado las bases para la creación de programas con los mismos fines, en El Salvador, Guatemala y Honduras tenemos el plan "Mano Dura”, el plan "Súper Mano Dura", el plan "Mano Amiga"; en México el "Operativo Acero", el "Plan "Mérida" donde también ha tenido presencia el "Plan Cero Tolerancia" desplegado en EE.UU. y Canadá. Programas que han sido fuertemente cuestionados por organismos internacionales respecto a la presunta violación a los Derechos Humanos.

"A mi punto de vista, muchos andamos en la calle porque nos gusta, muchos porque no tenemos un hogar y muchos porque aunque nos quisiéramos calmar, la familia no nos deja ni la sociedad no nos deja, o sea que no es un problema de pandilla, sino de sociedad y si la sociedad nos diera la mano, muchos no anduviéramos en la calle, por decir nosotros"6.

Podemos ver que antes de ser mareros, los jóvenes son seres humanos con necesidades y sentimientos. Debemos apelar a la razón para lograr un trato que no los denigre ni los estigmatice, que las leyes realmente tengan en principio la idea de igualdad, y no sólo de ejercer el poder por el poder mismo.

\section{Las maras como victimarias}

En Latinoamérica especialmente en El Salvador, es a partir del año 1992

6. Trabajo de Campo, 2008. cuando las maras como sinónimo de pandillas violentas empiezan a ser difundidas en los medios, aquí debemos ser precavidos, debemos considerar muy en particular primeramente el contexto histórico. Hacia el siglo XIX, en el contexto latinoamericano se encontraban las Provincias Unidas de Centroamérica, que en 1824 cambian de nombre a República Federal de Centroamérica, donde se incluía cinco estados: lo que hoy es El Salvador, Guatemala, Honduras, Nicaragua y Costa Rica ${ }^{7}$, dichas condiciones que llevan a desarrollar una serie de conflictos bélicos, que por una parte confrontaban a los grupos de poder principalmente criollos con diferentes acepciones políticas, y por el otro lado a la población indígena.

Estas discontinuidades en el contexto centroamericano fueron la base de los movimientos que durante el siglo XX, llevarán a confrontar a la clase política con el poder popular ${ }^{8}$. A medida que el conflicto avanzaba, la guerrilla Frente de Liberación Nacional Farabundo Martí (FLNFM) obtuvo apoyo indirecto y directo también de Cuba, y el pleno respaldo del régimen sandinista de Nicaragua, una vez en el poder tras el derrocamiento de la dictadura Somocista en 1979.

Un atenuante más a la situación de Centroamérica, fueron las masivas deportaciones que Estados Unidos hizo de jóvenes algunos pertenecientes a las maras hacia sus países

7. MEDINA NÚÑEZ, Ignacio. El Salvador: Entre la guerra y la esperanza. Colección: Estudios Latinoamericanos/1, México: Universidad de Guadalajara, 1990.

8. Al respecto ver los trabajos de José Ventura, El poder popular en El Salvador, 1985; Asociación para el Avance de las Ciencias Sociales en GuatemalaAvancso. Por sí mismos. Un estudio preliminar de las "maras" en la ciudad de Guatemala. Cuadernos de investigación No. 4, Guatemala, 1988. 
de origen. Un hecho que a menudo es percibido como un factor directo para la proliferación acelerada de los actuales grupos mareros de la región fueron los cambios en la política estadounidense a partir del año 1992. A partir de 1996, los prisioneros una vez que cumplieron su período en la cárcel, fueron deportados a sus países de origen, donde los conflictos armados ya habían terminado, se estima que aproximadamente fueron $20 \mathrm{mil}$ centroamericanos deportados principalmente a El Salvador en el período de 2000 a 2004.

Factores adicionales a considerar en el ámbito latinoamericano son el crecimiento de la población urbana, que actualmente corresponde al $80 \%$ del total, el crecimiento de la economía informal, el desempleo juvenil y el aumento de los flujos migratorios. Adicionalmente, la región registra uno de los índices mundiales más elevados de violencia.

La Mara Salvatrucha 13 y la Mara Barrio 18, son dos maras delincuenciales y violentas que se han extendido desde EE.UU. hacia Centroamérica, primero dada la migración forzada de niños y jóvenes hacia los Estados Unidos por la guerra en El Salvador y los conflictos armados en Nicaragua, Honduras y Guatemala, donde adoptaron conductas violentas como mecanismos de defensa y luego por las deportaciones masivas de EE.UU. de los jóvenes quienes aprovechan la vinculación con las pandillas americanas para ejercer todo tipo de violencia en Centroamérica.

La pandilla Barrio 18, XVIII o Eighteen Street, de origen chicano y que dio apertura a jóvenes latinos entre ellos salvadoreños, fue en gran medida reconstruyéndose con gente no sólo de El Salvador sino de todo Centroamérica, lo que la ha convertido en la pandilla más grande de los Ángeles; la prensa americana como Los Angeles Times, The Daily y The Herald-Express, refieren que es de esta pandilla de donde se van a desprender un grupo de salvadoreños inconformes que darán inicio a la Mara Salvatrucha o MS-13, lo cual explica en principio la rivalidad a muerte entre estas agrupaciones lo que las ha llevado a consolidarse como fenómenos sociales transnacionales.

Las maras del tipo pandilleril son organizaciones de autodefensa juveniles en territorios enemigos, donde ser joven, sin recursos económicos -y más si se es migrante- tiene un alto costo de discriminación, donde "la única salida a la marginalidad tiene que romper la ley; donde la violencia, propia del sistema capitalista, es enfrentada con más violencia; donde la vida no vale nada, o más bien, donde se da el encuentro de la funesta realidad de saber que la muerte comienza a ser un negocio lucrativo"9.

Ambas maras cuentan entre sus filas con sujetos capaces de cometer todo tipo de actos delictivos, cargados de un alto grado de violencia, capaces de atacar a cualquier miembro de la sociedad, sean mujeres, niños, ancianos, etc. Entre sus actos podemos mencionar los asaltos a mano armada, extorsiones, secuestros, narcomenudeo, violaciones sexuales, asesinatos y actualmente el sicariato, es decir matones a sueldo principalmente de carteles de la droga. ¿Debemos tener alguna consideración hacia ellos?

9. CASTILLO BERTHIER, Héctor. Pandillas, jóvenes y violencia. En: Desacatos No. 14: Juventud, exclusión y violencia, Revista de Antropología Social, cuatrimestral, México, Ciesas, 2004, p. 106. 


\section{A manera de Conclusión}

A pesar de la conciencia de los líderes políticos, sociales y policiales de los países afectados sobre la diversidad de factores que inciden en el surgimiento y el desarrollo de las maras, la respuesta oficial se ha concentrado en la represión. Tomemos en cuenta que el surgimiento de las maras va de la mano con los cambios en el contexto sociocultural, económico y político.

La aplicación de políticas de mano dura y de cero tolerancia como respuesta para combatir la violencia de- rivada de las acciones de las maras $\mathrm{y}$ pandillas juveniles, ha tenido una repercusión negativa en la consolidación de fuerzas policiales "profesionales" y "respetuosas" de los derechos humanos, al menos es lo que se puede observar en las estadísticas oficiales de los gobiernos centroamericanos.

En mi propia experiencia, es sólo a través de darles la oportunidad a los jóvenes de las maras para que externen sus ideas, emociones y pensamientos como lograremos una mejor percepción del fenómeno y así poder combatirlo desde sus raíces.

\section{BIBLIOGRAFÍA}

CASTILLO BERTHIER, Héctor. Pandillas, jóvenes y violencia. En: Desacatos No. 14: Juventud, exclusión y violencia, Revista de Antropología Social, cuatrimestral, México: Ciesas, 2004.

LARA KLAHR, Marco. Hoy te toca la muerte. El imperio de las Maras visto desde dentro. México: Planeta, 2006.

THRASHER, Frederik M. The gang. A study of 1313 gangs in Chicago. Chicago: University of Chicago Press, 1927.

MEDINA NÚÑEZ, Ignacio. El Salvador. Entre la guerra y la esperanza. Colección: Estudios Latinoamericanos/1. México: Universidad de Guadalajara, 1990. 